\title{
HYPOPARATHYROIDISM PRESENTING WITH PREDOMINANT GI SYMPTOMS WITH DYSELECTROLYTEMIA
}

\author{
P. Dihingia¹, Pramod G. R², P. Goswami³ , S. Kar ${ }^{4}$ B. Agarwal ${ }^{5}$
}

\section{HOW TO CITE THIS ARTICLE:}

P. Dihingia, Pramod G. R, P. Goswami, S. Kar, B. Agarwal. "Hypoparathyroidism Presenting with Predominant GI Symptoms with Dyselectrolytemia". Journal of Evolution of Medical and Dental Sciences 2014; Vol. 3, Issue 67, December 04; Page: 14558-14561, DOI: 10.14260/jemds/2014/3955

\begin{abstract}
A 35 year old married Hindu female patient presented to the casualty with the chief complaints of recurrent episodes of vomiting for 3 weeks, pain abdomen, and involuntary spasms in both hands for 1 week. On examination mild epigastric tenderness was present, and Chvostek's and Trousseau's sign were present. On investigation USG abdomen showed cystitis. Serum calcium $6.9 \mathrm{mg} / \mathrm{dl}$ and corrected calcium was $7.5 \mathrm{mg} / \mathrm{dl}, \mathrm{Na}+115.4 \mathrm{meq}, \mathrm{k}+1.43 \mathrm{meq}$, S. P04- 7.6mg and serum creatinine was within normal limits. ECG showed u waves in chest leads. CT brain was normal. On subsequent examination serum sodium and potassium improved but serum calcium again decreased to 7.6. And during the whole course of treatment patient showed only intermittent improvement. Serum PTH was planned and it was very low i.e.0.3 pg/ml (15-68). Patient's thyroid function was within normal limit. In view of laboratory values showing severe hypocalcemia, hypoparathyroidism, and hyperphosphatemia, we considered the possibility of hypocalcemia secondary to idiopathic hypoparathyroidism. Patient was treated with high dose intravenous calcium (Calcium Gluconate) and Vitamin D (Calcitriol) in addition to receiving all supportive treatments. Intake of milk and milk products was restricted in view of hyperphosphatemia. She responded to above treatment and was discharged in a stable haemodynamic condition.
\end{abstract}

KEYWORDS: Hypoparathyroidism, Tetany, Hypocalcemia, PTH (parathyroid hormone).

INTRODUCTION: Hypoparathyroidism is decreased function of the parathyroid glands with underproduction of parathyroid hormone. ${ }^{1}$ The main symptoms of hypoparathyroidism are the result of the low blood calcium level, which interferes with normal muscle contraction and nerve conduction. As a result, people with hypoparathyroidism can experience paresthesia, an unpleasant tingling sensation around the mouth and in the hands and feet, as well as muscle cramps and severe spasms known as "tetany" that affect the hands and feet.1,2

Many also report a number of subjective symptoms such as fatigue, headache, bone pain and insomnia. Crampy abdominal pain may occur. Physical examination of someone with hypocalcemia may show tetany, but it is also possible to provoke tetany of the facial muscles by tapping on the facial nerve (a phenomenon known as Chvostek's sign) or by using the cuff of a sphygmomanometer to temporarily obstruct the blood flow to the arm (a phenomenon known as Trousseau's sign in latent tetany). ${ }^{3}$

A number of medical emergencies can arise in people with low calcium levels. These are seizures, severe irregularities in the normal heart beat, as well as spasm of the upper airways or the bronchi (both potentially causing respiratory failure). ${ }^{4}$

The condition can be inherited, but it is also encountered after thyroid or parathyroid gland surgery, and it can be caused by immune system-related damage as well as a number of rarer causes.5,6 The diagnosis is made with blood tests, and other investigations such as genetic testing. 
The treatment of hypoparathyroidism is limited by the fact that there is no artificial form of the hormone that can be administered as replacement; calcium replacement or vitamin D can ameliorate the symptoms but can increase the risk of kidney stones and chronic kidney disease.

A CASE REPORT: A 35 yrs old married Hindu female patient presented to the casualty with the chief complaints of recurrent episodes of vomiting for 3 weeks, there was associated pain abdomen. Patient also complains of involuntary spasms in both hands for 1 week. Patient gives history of similar complain a year back which subsided on taking some medications prescribed by local doctor and there was no history of recent thyroid/neck surgeries. On examination mild epigastric tenderness was present, and Chvostek's and Trousseau's sign were present.

On investigation her Hbwas 10.2gm\%, TC 12,300, DLC- N72 E2 L19 M7. Markers of inflammation were high ESR 120mmAEFH, CRP >4.8. ASO titre was $<200$, and Rh factor was negative. $\mathrm{X}$ rays of both hand with wrist joints showed periarticular osteoporosis. USG abdomen showed cystitis. Serum calcium $6.9 \mathrm{mg} / \mathrm{dl}$ and corrected calcium was $7.5 \mathrm{mg} / \mathrm{dl}, \mathrm{Na}+115.4 \mathrm{meq}, \mathrm{k}+1.43 \mathrm{meq}, \mathrm{S}$. P04- 7.6mg and serum creatinine was within normal limits. ECG showed u waves in chest leads. CT brain was normal.

Later the patient developed perioral tingling and nausea. In the meantime calcium, sodium, and potassium were replaced both intravenously followed by orally.

Electrolytes were repeated the following day $\mathrm{Ca} 2+7.2, \mathrm{Na}+123.9, \mathrm{~K}+1.56$. Total protein 6, S. Albumin 2.9, S. Globulin 3.1. Though the treatment was continued but the patients symptoms of hypocalcemia was not improving. The electrolytes were again repeated the next day, and though the electrolytes improved but the patient was still having symptoms (S.Ca2+ 9.1, S.Mg2+ 2.2, S. Lipase 36.5, S. Amylase 61.9).

On subsequent examination serum sodium and potassium improved but serum calcium again decreased to 7.6. And during the whole course of treatment patient shows only intermittent improvement. Serum PTH was planned and it was very low i.e.0.3 pg/ml (15-68). Patients thyroid function was within normal limit.

DISCUSSION: Hypoparathyroidism is an endocrine disorder that can be a result of diverse reasons. When no obvious cause is detected it is termed as the idiopathic variety.

Clinical manifestations in hypoparathyroidism result from hypocalcemia which leads to increased neuromuscular irritability and may present with circumoral numbness, paresthesias of the hands and feet, and muscular cramps, or when severe, with laryngospasm, focal or generalized tonic muscle cramps, or seizures, myocardial dysfunction and prolongation of the QT interval, while biochemical abnormalities reveal hyperphosphatemia, in addition to decreased detectable levels of serum parathyroid hormone and calcium.

Transient hypoparathyroidism with biochemical abnormalities is commonly seen $(>83 \%$ of cases) after thyroid surgery. However, our patient had no recent or remote history of thyroid/neck surgery or irradiation.

Congenital, genetic and hereditary, familial autoimmune, ${ }^{7}$ or infiltrative causes of hypoparathyroidism rarely present in advanced ages which manifest earlier, and were unlikely in our patient in the absence of suggestive family history.

Nutritional deficiency cannot be ruled out, especially in postmenopausal females in India. However, nutritional deficiency hypocalcemia would likely be associated with secondary 


\section{CASE REPORT}

hyperparathyroidism and hypomagnesemia. Hypomagnesemia alone may also result in increased neuromuscular irritability and secondary hypocalcemia in a diabetic patient has also been reported. ${ }^{8}$ However, the magnesium level of our patient was normal.

Patients with primary hypoparathyroidism have a lifelong risk of symptomatic tetany and patients should be advised to monitor serum calcium levels and they should be treated with adequate doses of calcium supplements and vitamin D. ${ }^{9}$

In view of laboratory values showing severe hypocalcemia, hypoparathyroidism, and hyperphosphatemia, we considered the possibility of hypocalcemia secondary to idiopathic hypoparathyroidism. Patient was treated with high dose intravenous calcium (Calcium Gluconate) and Vitamin D (Calcitriol) in addition to receiving all supportive treatments. Intake of milk and milk products was restricted in view of hyperphosphatemia. She responded to above treatment on second day of IV calcium therapy. She was discharged in a stable haemodynamic condition. On discharge, Serum calcium was $8.3 \mathrm{mg} / \mathrm{dl}$, Serum phosphorus was $6.5 \mathrm{mg} / \mathrm{dl}$.

CONCLUSION: In our region hypoparathyroidism presenting with dyselectrolytemia is very uncommon. Routine checking of serum calcium, phosphorus and PTH will help in the early detection of hypoparathyrodism and accordingly should be treated with calcium supplements.

\section{REFERENCES:}

1. Thakker RV. Genetics of endocrine and metabolic disorders: parathyroid. Rev Endocr Metab Disord 2004; 5: 37-51.

2. Dimich A, Bedrossian PB, Wallach S. Hypoparathyroidism, clinical observations in 34 patients. Arch Intern Med 1967; 120: 449-58H.

3. Fulop M, Zeifer B: Case report: extensive brain calcification in hypoparathyroidism. Am J Med Sci 1991, 302 (5): 292-295

4. Dedivitis RA, P fuetzenreiter EG, Jr, Nardi CE, Barbara EC. Prospective study of clinical and laboratorial hypocalcemia5.after thyroid surgery. Braz J Otorhinolaryngol. 2010; 76: 71-7.

5. Girija AS: Idiopathic hypoparathyroidism with extensive intracranial calcification associated with kinesogenicchoreoathetosis. J Assoc Physicians India 2000, 48 (9): 938-939.

6. Srivastava A, Ravindran V. Stridor secondary to hypocalcemia in the elderly: An unusual presentation. Eur J Intern Med 2008; 19: 219-20.

7. Brown EM. Anti-parathyroid and anti-calcium sensing receptor antibodies in autoimmune hypoparathyroidism. Endocrinol Metab Clin North Am. Jun 2009; 38 (2): 437-45.

8. Papaioannou A, Papantonaki S, Nyktari V, Psomopoulos H, Karatsis P, Fraidakis O, et al. Hypomagnesaemia associated with diabetes mellitus may cause laryngospasm. Acta Anaesthesiol Scand. 2006; 50: 512-3.

9. Al-Azem and A. A. Khan, "Hypoparathyroidism," Best Practice and Research: Clinical Endocrinology and Metabolism, vol. 26, no. 4, pp. 517-522, 2012. 


\section{CASE REPORT}

\section{AUTHORS:}

1. P. Dihingia

2. Pramod G. R.

3. P. Goswami

4. S. Kar

5. B. Agarwal

\section{PARTICULARS OF CONTRIBUTORS:}

1. Associate Professor, Department of Medicine, Assam Medical College, Dibrugarh.

2. Post Graduate Trainee, Department of Medicine, Assam Medical College, Dibrugarh.

3. Assistant Professor, Department of Medicine, Assam Medical College, Dibrugarh.
4. Registrar, Department of Medicine, Assam Medical College, Dibrugarh.

5. Post Graduate Trainee, Department of Medicine, Assam Medical College, Dibrugarh.

\section{NAME ADDRESS EMAIL ID OF THE CORRESPONDING AUTHOR:}

Dr. Prasanta Dihingia,

Associate Professor,

Department of Medicine,

Assam Medical College,

Dibrugarh, Assam-786002.

Email:drprasantadihingia@gmail.com

Date of Submission: 25/10/2014.

Date of Peer Review: 26/10/2014.

Date of Acceptance: 24/11/2014.

Date of Publishing: 04/12/2014. 